\title{
A Contrastive Study of Conceptual Metaphor in Chinese and English
}

\author{
Rui Li \\ School of Foreign Languages \\ Henan University of Chinese Medicine \\ Zhengzhou, Henan, China
}

\begin{abstract}
In 1980, George Lakoff and Mark Johnson's Metaphors We Live By made conceptual metaphor a hot research issue. Conceptual metaphor shows universality as well as variation among different languages. This paper compares English and Chinese conceptual metaphors and tries to discuss whether the universality of the metaphor or the variation of the metaphor takes a more dominant place. In addition, this paper explores the specific reasons behind these variations, hoping that this study may shed some light on the understanding of the nature of conceptual metaphors.
\end{abstract}

Keywords—conceptual metaphor; universality; variation

\section{INTRODUCTION}

The classical studies of metaphor can be traced back to Aristotle. In 1980, with the publishing of Lakoff and Johnson's Metaphors We Live By, the cognitive view of metaphor appeared. The Theory of Conceptual Metaphor distinguishes itself from the traditional way of studying metaphors in that it regards metaphor as a cognitive phenomenon rather than a mere linguistic phenomenon. Conceptual metaphor is taken as a way of conceptualization, a way of thinking, and a fundamental cognitive device we use to conceptualize the world. It can be seen as a cultural phenomenon from a deeper level.

Since all the human beings live in the same world, they may have similar impression, imagination and life experience among people from different places. So some conceptual metaphors must appear to be at least nearuniversal. But in fact, you can always find that some variations in metaphor among people from different cultures. What are the specific reasons behind these variations? Which one takes a more dominant place, the universality of the metaphor or the variation of the metaphor? This paper will use English and Chinese languages as the examples to answer the above questions, hoping that this study may shed some light on the understanding of the nature of conceptual metaphors.

Fund Project: This paper is the phase achievement of Scientific Nursery Project of Henan University of Chinese Medicine"A Survey into Meta-professional Competence of Teachers of English for TCM Purpose Under Hierarchy of Needs Theory"

(Project No.: MP2016-54)

\section{CONCEPTUAL METAPHOR AND CULTURE}

Based on many linguistic evidences, Lakoff and Johnson in the book Metaphors We Live By claim that conceptual metaphor is a means of understanding one conceptual domain in terms of another conceptual domain (Lakoff and Johnson 1980:5). On basis of that, Lakoff defines conceptual metaphor as the cross-domain mapping from the target domain to the source domain in the conceptual system (Lakoff, 1993). Through conceptual metaphor mapping, the abstract and complex target domain is understood in terms of the concrete and simple source domain which reveals the deep mechanism in our conceptual system with regard to how human beings perceive and understand the world.

Concerning the relationship between conceptual metaphor and culture, Ning Yu offers us a good answer: "If culture is the reflection and pattern of thinking and understanding, and if thinking and understanding can be and are sometimes inevitably metaphorical, then culture and metaphor will also fall into a relation of mutual promotion or restraint" (Yu 1998: 82). Firstly, culture shapes and restraints the conceptual metaphor, that is, conceptual metaphor has a very strong cultural tag and it is influenced by culture. The reason lies in the fact that conceptual metaphor is based on our physical experience through our body's interaction with social and cultural environment. Social background, social value, cultural knowledge should be taken as important factors when constructing conceptual metaphor and metaphorical expressions. Secondly, it is conceptual metaphor systems that constitute the culture. The previous conceptual metaphor based on cultural experience will later serve as the basis for another new conceptual metaphor. This process going on, the conceptual metaphor systems were set up to constitute the culture. Thirdly, conceptual metaphor is the carrier of culture. Through the conceptual metaphor system, we get a general picture of how the native people think and look at things. For example, Thomas Jefferson's famous conceptual metaphor SEPERATION IS A WALL. Originally, it was used to refer to "separation of religion from politics" against the severe religious persecution background. Now many linguistic expressions under this conceptual metaphor such as "mortar, height, porous, impregnable, break down, knock down" appear. The conceptual metaphor has become a carrier of culture. 
To sum up, culture and conceptual metaphor are closely related. Through comparing English and Chinese conceptual metaphors, this paper explores the specific cultural reasons behind similarities and variations of the two languages, hoping that this study may shed some light on the understanding of the nature of conceptual metaphors.

\section{COMPARISON BETWEEN ENGLISH AND CHINESE CONCEPTUAL METAPHORS}

\section{A. Metaphors for Happiness and Anger}

Firstly, let's look at the conceptual metaphors of happiness. In English, happiness is typically expressed by employing the concepts of "up", "light". Look at the following examples:

HAPPY IS UP: They're all in high spirit.

My spirits rose.

That boosted up my spirits.

HAPPY IS LIGHT: He beamed with a smile.

She lit up upon hearing the news.

seeing her daughter.

Her eyes were shining/sparking when

These metaphors also exist in the conceptualization of happiness in Chinese. Here are some Chinese examples:

HAPPY IS UP: Ta hen gao xing.

Zhe ge hao xiao xi rang ta men qing $x u$ gao ang.

Zhe bu dian ying ti qi le wo de xing qu.

HAPPY IS LIGHT: Ta men ge ge xing gao cai lie.

Ta xiao de rong guang huan fa.

liang le.

Kan dao er zi, ta de yan jing dou

From the above examples we can see Chinese shares with English all the basic metaphor source domain for happiness: up, light.

But Chinese has some unique expressions which is absent in English. For example, the Chinese sentence: Ta xin hua nu fang. According to Ning $\mathrm{Yu}$, the metaphor reflects "the more introverted character of Chinese." It can serve as a contrast to the English metaphor "Being happy is being off the ground", which reflects the relatively "extroverted" character of speakers of English. (Zoltan Kovecses, 2002)

Concerning the metaphor of anger, we can also see the universality of conceptual metaphor among different languages. Chinese and English both employ the concept that "anger is a pressurized container".

English: He was bursting with anger.

Chinese: Wo xin li you qi.
Though both the Chinese and English consider that "anger is a pressurized container", there are some tiny variations: in English anger is a hot fluid in a container, such as "You make my blood boil". As for Chinese anger, King and $\mathrm{Yu}$ suggest that the Chinese concept is bound up with the notion of "qi", that is, the energy that flows through the body. (Zoltan Kovecses, 2002)

\section{B. Metaphors for Love}

1) Through searching the data, I find the following similarities existing between Chinese and English metaphors for love

a) Both English and Chinese usually use the concept of "journey" to refer to love

English: It's been a long, bump road.

\section{We can't turn back now.}

We'll just have to go our separate ways.

Chinese: Qing lu jian xin.

Ta men yi qi zou guole 50 duo nian de li cheng.

Qing chang lu geng chang.

b) Fluid is always employed as the concepts of love English: The young boy is filled with love.

They fell in love at first sight.

Chinese: Ta men zhui ru le ai he.

Ta men qing shen si hai.

c) Love is plant, which means that love is lifelike

English: Burns (English poet): A Red, Red Rose.

Our love flowered.

Chinese: Cui hu (Chinese poet): Ren mian tao hua xiang ying hong.

Ta men shi yi dui bing di fu rong.

2) English and Chinese also have many unique metaphors respectively. Compare the following groups of examples:

a) Chinese: Qing si jian bu duan, li hai luan.

English: I treasured this love. I paid a lot for so little love.

What causes the contrast in the above metaphors in English and Chinese? We can see that historically, China is an agricultural country, where the silk is abundant. So people in China likes to use "can, si" to express love. While commodity economy is highly developed in western world, people are more likely to compare love to something valuable.

b) Chinese: Qian li yin yuan yi xian qian.

English: Marriage is a durable bond between two people. 
Because of Chinese traditional culture and Chinese people's pursuit of harmony, they believe love means "yuan fen". But for the English people, living in a highly developed trading world, they tend to think love or marriage is the bond.

Besides, in Chinese, there are some unique metaphors, such as "Zai tian yuan zuo bi yi niao, zai di yuan wei lian li $z h i$ "。 They are all closely connected with specific Chinese culture.

\section{Metaphors for Death}

English and Chinese usually employ similar source domain in understanding death, such as "the end of the journey", "the loss of something valuable", "the end of the play", "the extrication of the burden and bondage". These metaphors reflect the same life experience of people.

However, there are also some variations: Firstly, Chinese has some unique metaphors, such as they consider death is the collapse of a tall and heavy object. So they call the death of the emperor "jia beng". Secondly, though English and Chinese all believe death is the end of the journey, English has no clear description of the death journey, but in Chinese we have "huang quan lu, gui men guan" Thirdly, English believe the end of the death journey is "God the father's house", while in Chinese it is "xian you, sheng tian", that's because most western people believe in Christian, but most Chinese believe in Buddhism and Taoism.

\section{CONCLUSION}

All in all, we can see compared with the variation of the metaphor, the universality of the metaphor takes a more dominant place. This is due to the fact that we live in the same world, and have similar life experience. However, since different culture, history, custom, specific environment affects people's thoughts to a certain extent, there are variations in metaphor among different languages.

\section{REFERENCES}

[1] George Lakoff and Mark Johnson. Metaphors We Live By. [M]. Chicago and London, The University of Chicago Press, 2003.

[2] Zoltan Kovecses. Metaphor: A Practical Introduction. [M]. New York: Oxford University Press. 2002.

[3] Shu Dingfang. Research on Metaphors. [M]. Shanghai: Shanghai Foreign Language Education Press, 2000. 